cloths, with the view of bringing down the fever, and there followed an immediate and steady fall of temperature; and in the second case, the quinine, digitalis, and opium having failed to counteract the fever, iced cloths to the abdomen were superadded, upon which the temperature fell in less than twenty-foul hours from $104^{\circ}$ to $98^{\circ} 2^{\circ}$, and we had no difficulty thereafter in completely preventing any undue elevation of temperature.

Such, then, are the kind of cases which should be brought under the notice of those who, in these days of scepticism, are inclined to sneer at the efficacy of drugs.

\section{DISLOCATIONS OF THE THIGH : THEIR MODE OF OCCURRENCE, AND THE METHOD OF REDUCTION BY MANIPULATION.}

BY HENRY MORRIS, M.A., M.B. LOND., EMCTURER ON ANATOMY AT, AND ASSISTANT SURGEON TO, THE MIDDITSEX HOSPITAX.

THERE is one passage in Mr. Callender's communication on hip dislocations in THe LaNcet of March 17th which might lead to unnecessary confusion in the minds of anatomists, as well as of surgeons, and as his remarks have reference to me, I think I might take some notice of them.

It is stated, with reference to reducing hip dislocations, that the movement of the thigh, when bent up in extreme fexion over the opposite one, into a line parallel to the long axis of the body, is not abduction. As this movement can be made at any normal hip.joint, it must be one of the movements of which a ball-and-socket joint is capable. Now these movements, as we all know, are circumduction, rotation, and the angular movements, and these latter are flexion, extension, adduction, and abduction. But it will be granted that the movement in question is neither rotation, flexion, extension, nor adduction. Nor is it circumduction, though it can, and often is, made one of the stages of circumduction. What, then, can it be but abduc. tion? Circumduction is a composite movement made up of the several angular movements, and the particular stage of it at which the flexed and adducted thigh is carried outwards into the line parallel to the long axis of the body is abducfion. To say that it is not is as strange as saying that flexion does not begin until the angle formed between the thigh and trunk is less than $135^{\circ}$, or less than a right angle, or than any other angle, selected at the fancy of the individual. As the undoing of extension is from the first flexion, so the undoing of adduction is from the first abduction; and abduction of the thigh commences directly, the adducted limb is moved away from the mesial plane of the body. This description is in accordance with that given in Quain and other anatomical works, and with the action of the muscles producing the movement. But Mr. C.llender's definition of abduction refutes itself. He says, "Abduction, if it means anything, is a movement outwards from the line of, or lines parallel with, the long axis of the body, of which movement, in the case of the thigh, the head of the femur is the centre; but in circum. duction the head of the bone is forced to travel round the acetabulum, and is, therefore, in itself no centre of motion." If Mr. Callender, standing, for instance, in the theatre of St. Bartholomew's Hospital, will imagine a line, or lines, drawn parallel to the long axis of his own body, say in the adjoining passage or the street beyond, he will, I think, be convinced at once that he cannot move bis thigh outwards from such lines; though to abduct, according to his own definition, he should be able to do so; and, further, he will then, I think, admit that there must be some hard and fast line to which the term " movement outwards" must refer. By common consent this is a vertical line, drawn through the centre of the body-i.e., the long axis of the body; or, in other words, the mesial plane of the body. Properly speaking, there is only one long axis of our body. When, therefore, Mr. Callender says, "The moment the surgeon moves the limb beyond this line of the long axis of the body he overacts his part," he is unfortunate in his phraseology; for how can the surgen bring the thigh from the position supposed into one parallel to the long axis of the body, without taking it beyond the line of the long axis of the body, and, therefore, without overacting his part?

I would also point out that in circumduction, as in abduction, the head of the femur is the centre or pivot of movement; is, in fact, in circumduction, the apex of the cone described by the shaft; only, during the reduction of dislocations this centre, like the "pivot man" of a company of soldiers, is a shifting one in circumduction, and in abduction also. Mr. Callender tells us that circumduction is not rotation outwards. This was scarcely necessary. He also suggests that through these words I have been led into a misapprehension; but until reading his remarks I did not think it possible that any misapprehension respecting their meaning could arise.

If I understand aright, Mr. Callender intends his last to be a corroboration of his earlier paper. He says, "My views are in accord with those of wy colleagues (now and when the late Mr. Coote was one of them) as to the manœuvre to be effected by manipulation"; and, again, "there was no difference as to our views between Mr. Coote and myself." This being so it is obvious that the author's language completely disguised his thoughts, for it is a fact that $\mathrm{Mr}$. Coote, in his paper, recommended outward rotation, and thought that the capsule was torn at the inner and posterior part, but not at the anterior or outer part of the joint; whereas Mr. Callender in his paper condemned abduction (though he practised it) and rotation outward (making use of both terms), and stated it as his opinion that the capsule can never be an obstacle to reduction, because the violence which causes the dislocation "ensures that the capsular ligaments shall be torn to pieces." Having already given the exact references to these papers, I will not quote again from them, but will here only remark that the accident which Mr. Callender says is likely to be caused, while reducing dorsal dislocations by outward rotation, will, in my opinion, be avoided by it. After the head of the femur, by flexion and abduction, has been brought to the thyroid notch-i.e., to the spot at which it always escapes from its socket, -it will be at once returned into the acetabulum by rotating outwards the thigh just before beginning to extend it.

I have certainly been surprised to learn that Mr. Callender, when writing in 1868, took it for granted that Prof. Fabbri's views were well known to the profession, and that he should now write of Fabbri's method - " It is referred to (besides the few remarks by Mr. Coote and by myself) in Holmes's work on "Surgery, its Principles and Practice." "The latter has only been out about a year, and in it, as I have before stated, Mr. Holmes regrets that Fabbri's work is so little known in this country, it never having been translated into Fnglish; the "few remarks by Mr. Coote" are a distinct enunciation of Fabbri's views; while from beginning to end of Mr. Callender's paper there is not a single allusion, direct or indirect, either to $\mathrm{Mr}$. Coote or to Prof. Fabbri. This paper gives a report of a case of so-called "dislocation into the ischiatic notch," in which reduction by manipulation had been tried unsuccessfully before, and by Mr. Callender after, admission in to the hospital, but was uitimately effected "after the patient had rested for sevaral days"; it also contains some general remarks on the diffculties of reduction; and, lastly, there is an account of the danger of abducting and rotating during manipulation, together with a description of the method by which reduction in this particular case was at last acenmolished.

But Mr. Callender now says that he is, with Mr. Willett, surprised to find that Fabbri's views had not been long ago before the profession. It surely did not need the discussion on my paper to make this evident. Since Professor Fabbri and $\mathrm{Mr}$. Coote wrote, new works on Surgery and new editions of old works have been published, and yet in which of them has Mr. Callender or Mr. Willett been able to find Fabbri's views quoted or adopted? On the other hand, we have seen that the name of Fabbri had been forgotten by those who witnessed his demonstrations at St. Bartholomew's Hospital; and in the last edition of the System of Surgery Mr. Coote is referred to, not by name, but as " a writer" whose views do not require serious consideration.

Mr. Callender gives a list of four authors who have de- 
scribed "the treatment by this form of manipulation." What form? Not Mr. Callender's, certainly. On looking to Prof. Spence's work (1871 ed.) - the first on the list-I find the following passage: "When there is any difficulty in attempting to reduce the dislocation by the hand, we should try it with the pulleys." He then goes on to say, but without definitely recommending, and without explaining the principle of, manipulation, that by "flexing it (the thigh) slowly upwards over the pubis to the umbilicus, then ab. ducting and rotating outwards, the reduction is accomplished." The two very movements which Mr. Callender insista ought not to be made. There is not a syllable about Fabbri.

Very many names might have been mentioned of those who have advocated manipulation, but I bave shown previously that it must not be inferred that even those who have practised the correct method have explained and based their practice upon the true ground-namely, that, as all dislocations are primarily downwards, the head of the femur has to be got down to the lower part of the acetabulum because the hole in the capsule is on that side, and on that side only; and Mr. Callender cannot, I am sure, mean to imply that each of the authors he quotes bas taken this view, although the context of his statement would lead one to draw that conclusion.

I am at a loss to see how Mr. Callender can reconcile his "note on the practical point" to which he has drawn attention-and which comes to this: do not abduct beyond the line of the body, and do not rotate the thigh outwardswith Fabbri's plan of manipulation, as stated by $\mathrm{Mr}$. Coote, in which rotation outwards (I do not mistake the term) is a leading feature; or his views respecting the entire destruction of capsule wlth Fabbri's principle of manipulation. I regret the confusion which may possibly arise from $\mathrm{Mr}$. Callender's interpretation of the words abduction and circumduction; but I am very glad to find that the theory that there is only one primary dislocation at the hip, and that all the rest are secondary thereto, has his support and that of all his colleagues.

Mansfield-street, Cavendish-square.

\section{CASE OF}

\section{PROGRESSTVE PERNICTOUS AN AEMTA SUC- CESSFULLY TREATED BY IMMEDIATE TRANSFUSION.}

Bx T. R. GLYNN, M.B. LoND.,

PHYSICIAN WO THF LTVBRPOOT ROYAI INFIRMARY.

For many of the particulars of this case I am indebted to Mr. Gorst, one of the house-physicians of the infirmary.

John F-, age forty-two, engineer, admitted Nov. 13th, 1876, into the Liverpool Royal Infirmary. The patient had followed his occupation on board ship for twenty years; for seven years sailing between British ports, for seven years between Liverpool and New York, and for the last six years to ports in the Mediterranean. Till recently he had enjoged excellent health; never had ague or any other serious illness; family history good.

History of illness.-Fourteen months ago he found that he was losing strength, becoming pale and thin, that his breath was short, and his heart beat violently on any exertion. $\mathrm{He}$ was under the care of a medical man for seven months, and improved, so that he was able to resume work; he continued it for ten weeks, and then gave up completely.

On admission he was much emaciated; his face was colourless; his lips pale; feet and ankles œdematous ; pulse soft, 90 ; respiration hurried, especially on exertion ; temperature normal ; tongue clean; urine normal in quantity, very pale, sp. gr. 1012, contained no albumen. Physical examination: splenic dulness somewhat increased; bepatio dulness normal; loud systolic murmur over base of heart and vessels in neek; impulse not displaced. On examination of the blood by the microscope, the white corpuscles were found to be not increased in number; the red, collected here and there into rouleaux, were decidedly diminished in number, but regular in shape. The patient complained of reat weakness, frontal headache, dizziness, impairment of vision and hearing, numbness of fingers, loss of appetite, \&c. He was ordered quinine and iron, and a liberal diet, containing eggs and port wine.

He, however, gradually became paler, weaker, thinner, and worse in every way, and was compelled to stay in bed. This treatment was continued some weeks, then phospho. rated oil was given, $\frac{1}{37} \mathrm{gr}$. of phosphorus after meals, as well as the iron between meals. There was no improvement, and after a fortnight's trial, as the phosphorus seemed to irritate the stomach, and increase the dyspeptic symptoms from which he suffered, it was omitted.

On Dec. 16th he was propped up in bed. Complexion and surface of body of a pale yellowish-white colour; fingeruails, lips, and mucous lining of cheeks white, or almost so. Breathing hurried; temperature below normal. Slept badly; dyspnoa increased at night; suffered from nightmare ; was very restless, " his head being light." Respiration about 30. Complained of cough; expectorated some frothy mucus. Small mucous râles heard over bases of lungs. Pulse 100, very small and soft. Appetite bad; indigestion troublesome; vomited once or twice. Voice weak; sight dim; hearing bad; noises in the ears. Complained of much dizziness, and weight across the front of the chest. Ordered a mixture of ether and ammonia, which somewhat relieved the breathing.

He continued to fail during the next four days, and on the 20 th he suffered from constant orthopncea; was very deaf, drowsy, and listless; could scarcely move without help. The numbness of his fingers almost amounted to complete loss of sensation; swimming sensation in head very bad; "felt his sight was going." Palse 112, smaller and weaker; urine small in quantity, sp. gr. 1007, very pale, no albumen. Physical signs the same; tenderness overs liver on percussion.

I then determined to transfuse. A healthy man from one of the surgical wards, who was suffering from a stiff knee, volunteered to give the blood. Mr. Paul, resident medical superintendent, assisted by Messrs. Gorst and Jones, housephysicians, performed the operation. The giver of the blood was placed on a bed by the side of the patient, their right arms being close together. A veling's instrument was used. It was filled with a warm saline solution. The veins were opened, the cannulæ inserted and held by the assistants, and the operation carried on in the usual way. The quantity of fluid which could be driven through the instrument on compressing the ball was measured, and the number of compressions counted. Between eighteen and twenty ounces were injected. The operation lasted about thirteen minutes. No hitch occurred, and no blood was lost but what escaped before the cannulæ were inserted. The operation was continued till the patient manifested some uneasiness. He complained of a sense of oppression about the chest, and requested to be raised higher in the bed. In a little while, however, he expressed himself as feeling more comfortable. His pulse, which very perceptibly gained in volume and strength during the operation, was now much stronger108. His head was less light, and he breathed easier. The same evening his skin was hot; the temperature was $102^{\circ}$; pulse 112, decidedly stronger and fuller; respiration 30 ; coughing a great deal and expectorating much thin colour. less frotby mucus; complained of great thirst.

Dec. 2lst.-Passed a much better night; slept well at times. Head much better; feeling of numbness in the fingers less; sight much improved; hearing better; expression cheerful; temperature $103^{\circ}$; respiration 34 ; cough and expectoration about the same; pulse 120 , and continues stronger (spbygmographic tracing exhibited a marked dicrotic wave); appetite much improved; passed more urine The same evening the temperature was $101 \cdot 4^{\circ}$, the pulse 124, and the respiration 32

22ad.- - Had a good night; generally more comfortable, and in good spirits; respiration 32 ; cough still troublesome; expectoration less, same in character; pulse 116 ; temperature in the morning $99^{\circ}$, evening $102^{\circ}$.

23rd.- States that he feels stronger; there is a slight tinge of colour on the cheeks; the lips and nails reddish can sit up in bed without feeling giddy; slept through most of the night; temperature in the morning $99^{\circ}$, in the evening $100^{\circ}$; pulse 100 , stronger; respiration 24 ; cough better; urine darker in colour, specific gravity 1012, and containing no albumen. 